\title{
Nicotinic Acid-Mediated Activation of Both Membrane and Nuclear Receptors towards Therapeutic Glucocorticoid Mimetics for Treating Multiple Sclerosis
}

\author{
W. Todd Penberthy \\ Department of Molecular Genetics, Biochemistry, and Microbiology, University of Cincinnati, 231 Albert Sabin Way P.O. Box 670524, \\ 2938 CVC Mail Loc-0524, Cincinnati, Ohio 45237, USA \\ Correspondence should be addressed to W. Todd Penberthy, wtpenber@yahoo.com
}

Received 1 December 2008; Accepted 22 February 2009

Recommended by Antonio Brunetti

\begin{abstract}
Acute attacks of multiple sclerosis (MS) are most commonly treated with glucocorticoids, which can provide life-saving albeit only temporary symptomatic relief. The mechanism of action (MOA) is now known to involve induction of indoleamine 2,3-dioxygenase (IDO) and interleukin-10 (IL-10), where IL-10 requires subsequent heme oxygenase-1 (HMOX-1) induction. Ectopic expression studies reveal that even small changes in expression of IDO, HMOX-1, or mitochondrial superoxide dismutase (SOD2) can prevent demyelination in experimental autoimmune encephalomyelitis (EAE) animal models of MS. An alternative to glucocorticoids is needed for a long-term treatment of MS. A distinctly short list of endogenous activators of both membrane G-protein-coupled receptors and nuclear peroxisome proliferating antigen receptors (PPARs) demonstrably ameliorate EAE pathogenesis by MOAs resembling that of glucocorticoids. These dual activators and potential MS therapeutics include endocannabinoids and the prostaglandin 15 -deoxy- $\Delta^{12,14}-\mathrm{PGJ}_{2}$. Nicotinamide profoundly ameliorates and prevents autoimmunemediated demyelination in EAE via maintaining levels of nicotinamide adenine dinucleotide (NAD), without activating PPAR nor any G-protein-coupled receptor. By comparison, nicotinic acid provides even greater levels of NAD than nicotinamide in many tissues, while additionally activating the PPAR $\gamma$-dependent pathway already shown to provide relief in animal models of MS after activation of GPR109a/HM74a. Thus nicotinic acid is uniquely suited for providing therapeutic relief in MS. However nicotinic acid is unexamined in MS research. Nicotinic acid penetrates the blood brain barrier, cures pellagric dementia, has been used for over 50 years clinically without toxicity, and raises HDL concentrations to a greater degree than any pharmaceutical, thus providing unparalleled benefits against lipodystrophy. Summary analysis reveals that the expected therapeutic benefits of high-dose nicotinic acid administration far outweigh any known adverse risks in consideration for the treatment of multiple sclerosis.
\end{abstract}

Copyright (C) 2009 W. Todd Penberthy. This is an open access article distributed under the Creative Commons Attribution License, which permits unrestricted use, distribution, and reproduction in any medium, provided the original work is properly cited.

\section{Multiple Sclerosis Treatment and Functional Transcriptomics}

Multiple sclerosis (MS) is the most common demyelinating disease of the central nervous system. It is a progressive disease with no known cure. MS results in scarring of CNS tissues termed sclerosis due to autoimmune-mediated attack of myelin-forming oligodendrocytes and/or myelin sheaths by autoreactive $\mathrm{T}$ cells. The disease affects more than 2.5 million people worldwide; $30 \%$ of MS patients eventually develop paralysis and become wheelchair bound for the rest of their lives $[1,2]$.
Glucocorticoids are the primary pharmacotherapeutic approach used to provide relief from acute attacks of MS and are the most commonly prescribed drugs in the world for treating autoimmune disorders in general (for a review [3]). While we are far away from a comprehensive picture of how glucocorticoids control neuroinflammation, recent studies have revealed central roles for indoleamine 2,3dioxygenase (IDO; $[4,5]$ ) and interleukin-10 (IL-10; [6]). The importance of IDO in estrogen-mediated suppression of EAE pathogenesis was demonstrated previously [7]. IL10 signaling is required for patients to respond to glucocorticoid treatment [6], while IL-10-mediated induction 
of heme-oxygenase-1 (HMOX-1) is required for IL-10 to exert its anti-inflammatory activity [8]. Increases in HMOX-1 have recently been shown to reverse paralysis and prevent relapse in animal models of MS [9]. Thus, by boosting IDO and IL-10 or HMOX-1, greater therapeutic benefit against autoimmune demyelinating disease may be achieved. Alternative clinical MS therapeutics have also been shown to work via induction of IL-10 or IDO. This includes the amino acid copolymer glatiramer acetate [10] or interferons [11-18], respectively. It seems difficult, however, to replicate the endogenous anatomically localized cellular production of interferon via pharmacological approaches. Interferon treatment is associated with complications, some of which can be quite serious [19]. Ultimately, no pharmacological agent has been proven to be clinically effective in patients during the progressive stages of MS [20].

The most common animal model of MS involves injection of myelin sheath-associated epitopes into mammals, which results in a dose dependent experimental autoimmune encephalomyelitis (EAE) (for a review see [21]). Lymphocyte-mediated demyelination proceeds around blood vessels of the CNS, leading to autoimmunemediated paralysis typically 10 days to three weeks postinjection. EAE has been successfully used in the development of clinical therapeutics [22]). Studies examining the pharmacology of the endogenous PPAR $\gamma$ activators have consistently revealed that the endogenous molecule 15-deoxy$\Delta^{12,14}$-prostaglandin $\mathrm{J}(2)\left(15 \mathrm{~d}-\mathrm{PGJ}_{2}\right)$ can ameliorate the MS clinical symptoms in EAE [23-27]. 15d-PGJ 2 is the most known potent endogenous activator of PPARs identified to date [25]. By focusing on endogenous molecules, we can better understand the inherent mechanisms by which the body maintains good health. This includes the endogenous PPAR activators $15 \mathrm{~d}-\mathrm{PGJ}_{2}$, two endocannabinoids (anandamide and 2-arachidonoylglycerol; 2-AG), and nicotinic acid, which stimulates the localized production of $15 \mathrm{~d}-\mathrm{PGJ}_{2}$ restricted to professional antigen presenting cells.

PPAR activators are well known for their ability to correct dyslipidemia [27]. Nicotinic acid indirectly activates PPAR $[28,29]$ and corrects dyslipidemia, raising high-density lipoprotein (HDL) concentrations to a greater degree than any known pharmaceutical [30]. The other most common nicotinamide adenine dinucleotide (NAD) precursor, nicotinamide, provides dramatic protection against demyelination and improves behavioral deficits in EAE [31]. Unlike nicotinic acid, nicotinamide provides little benefit against dyslipidemia since it does not bind to the high-affinity nicotinic acid G-protein-coupled receptor, and therefore nicotinamide does not activate PPAR $\gamma$. By contrast, nicotinic acid has not been systematically examined in animal models of MS or in the clinic.

Either nicotinamide or nicotinic acid can serve essential functions as a dietary precursor to NAD in the cell. Nicotinic acid is the most preferred substrate in evolution based on metabolite $[32,33]$ and comparative genomic studies examined to date (presentation by Mathias Ziegler at PARP 2008 meeting, Tucson, Ariz, USA). In glia, nicotinic acid provides greater levels of NAD biosynthesis per mole than nicotinamide or tryptophan by 200 - and 500-fold, respectively [34]. Furthermore, neurons appear distinctively inefficient in their ability to convert dietary NAD precursors to NAD [35].

Accordingly, supraphysiological elevations of NAD are known to exert tremendous neurotrophic activity. When a neuron is cut with a razor blade, degeneration of axons occurs typically within one day. Genetic triplication of the nuclear generating enzyme nicotinamide adenine mononucleotidyl transferase-1 (NMNAT1) however delays neurodegeneration for 2-3 weeks after excision [36, 37]! This dramatic effect is mediated via NAD-dependent activation of SIRT-1. Functioning as a NAD-dependent histone deacetylase, SIRT-1 exerts global changes in the transcriptome that mimic caloric restriction (for a review of this process see [38]). Direct SIRT-1-mediated deacetylation of the liver $X$ receptor (LXR) leads to activation of LXR with effects on lipid homeostasis and ABCA1 gene regulation [39]. Similarly, SIRT-1 directly deacetylates and activates peroxisome proliferator-activated receptor-gamma, coactivator 1 $(\mathrm{PGCl} \alpha)$. Redistribution of the other nuclear NMNAT1encoding protein to the cytosol extends the delay in Wallerian degeneration up to seven weeks [40]! While SIRT-2 is present in the cytosol, it has not been determined which pathway is most integral to the cytosolic pathway. Common to both nuclear and cytosolic forms, however, it is clear that NAD is the central to this neurotrophic activity.

Ultimately NAD serves crucial functions as a cofactor in over 200 redox reactions or as a substrate in three categorical enzyme classes: deacetylases (Sirtuins, e.g., SIRT-1), ADPribosyl transferases (e.g., PARP-1), and ADP cyclases such as CD38. The two most common MOAs for glia-killing neurons in brain pathologies involve the free-radical generating enzymes NADPH oxidase and iNOS [41]. Both of which can lead to increased PARP-1 activity. Thus pharmacological administration of the NAD precursor nicotinamide provides dramatic protection from the clinical signs of EAE in a dose-dependent manner, preventing behavioral defects, minimizing demyelination, and preventing death [31]. Detailed analysis of the pathways controlling NAD levels and function in the context of multiple sclerosis is reviewed elsewhere [42]. However, nicotinamide treatment does not result in the production of $15 \mathrm{~d}-\mathrm{PGJ}_{2}$ with concomitant activation of PPAR. Collectively these observations suggest even greater benefit against demyelinating disease from nicotinic acid treatment than with nicotinamide. In this review we explore nicotinic acid's effects compared to nicotinamide with focus on describing genes known to be of greatest interest to MS pathogenesis.

Interestingly, high doses of sustained nicotinamide administration (1-4 grams per day) were shown to provide remarkable relief in patients with rheumatoid arthritis in the 1940's [43]. Nicotinamide was then historically supplanted in the treatment of arthritis with the monumental discovery and development of powerful synthetic corticosteroids occurring thereafter.

Today, glucocorticoids remain a common treatment modality in the management of rheumatoid arthritis. However, the ability of nicotinamide to ameliorate the 


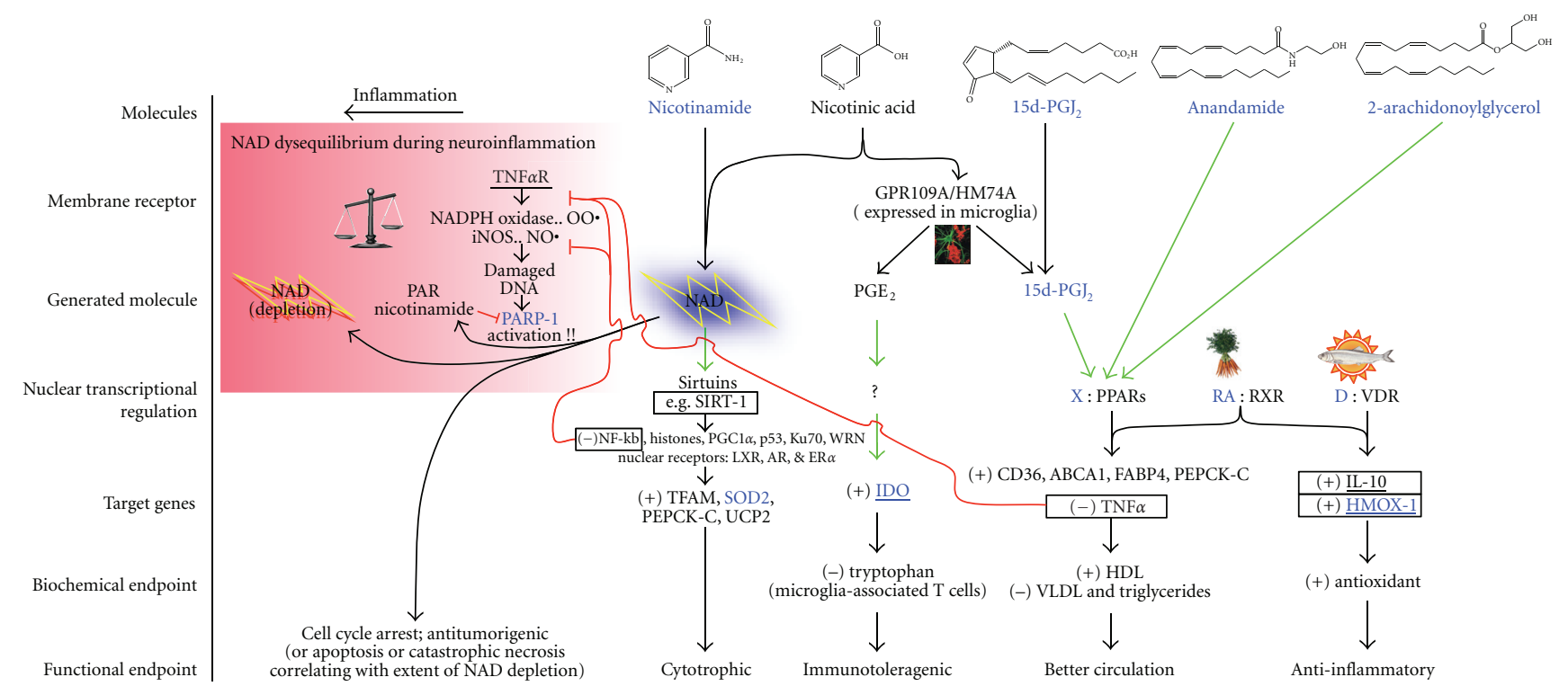

Figure 1: Unique mechanisms of action of nicotinic acid on immune function are shown. Nicotinic acid, but not nicotinamide, binds to the high-affinity nicotinic acid G-protein-coupled receptor HM74a/GPR109a that via calcium influx activates phospholipase $\mathrm{A}_{2}$. This ultimately leads to massive production and release of prostaglandins 15d-PGD $\mathrm{P}_{2}$ and $\mathrm{PGD}_{2}$ specifically from professional antigen presenting cells (macrophages, dendritic cells, and likely microglia [55]). Thus, nicotinamide, which also provides NAD, functions in part as a negative control for HM74a-dependent effects in experimentation. $\mathrm{PGE}_{2}$ was previously identified as promoting differentiation of plasmacytoid dendritic cells to a $\mathrm{T}$ cell toleragenic phenotype via induction of IDO expression and activity [49, 50]. Consequently nicotinic acid may provide a similar $\mathrm{T}$ cell toleragenic effect. $15 \mathrm{~d}-\mathrm{PGD}_{2}$ spontaneously degrades to produce $15 \Delta-\mathrm{PGJ}_{2}$, the most potent endogenous activator of PPAR $\gamma$. This may be central to the explanation of how nicotinic acid but not nicotinamide corrects dyslipidemia, raising HDL levels higher than any known pharmaceutical including all PPAR $\gamma$ agonists while also lowering LDL, VLDL, and triglycerides [30, 56].

autoimmune aspects of rheumatoid arthritis supports consideration of high-dose nicotinamide treatment in MS.

Nicotinic acid working through the high-affinity nicotinic acid G-protein-coupled receptor is particularly well suited for treatment of multiple sclerosis. The receptor is specifically expressed in one of the primary sources of MS pathogenesis (microglia). Furthermore this receptor is predicted to be involved in controlling the proliferation of autoreactive $\mathrm{T}$ cells via $\mathrm{PGE}_{2}$-mediated induction of IDO within the microglia (Figure 1). Nicotinic acid easily penetrates the blood brain barrier [44]. Nicotinic acid, but not nicotinamide, specifically binds to the high-affinity nicotinic acid G-protein-coupled receptor HM74a/GPR109a whose expression is largely restricted to professional antigen presenting cells including microglia. Since both nicotinamide and nicotinic acid contribute to greater NAD synthesis but only nicotinic acid signals through HM74a activation, we may consider nicotinamide in part a negative control for HM74a-mediated phenomena. Binding of nicotinic acid to $\mathrm{HM} 74 \mathrm{a}$ leads to a massive release of prostaglandin $\mathrm{PGD}_{2}$ and $\mathrm{PGE}_{2}$ [45-47]. These prostaglandins then mediate the vasodilation that generates a flushing side effect [48]. $\mathrm{PGD}_{2}$ produced from nicotinic acid signaling then degrades to form $15 \mathrm{~d}-\mathrm{PGJ}_{2}$, which activates PPAR $\gamma$ leading to increased expression of ABCA1 and CD36 in macrophages [28, 29]. The other prostaglandin $\mathrm{PGE}_{2}$ induces expression of IDO in dendritic cells, resulting in a toleragenic effects on local $\mathrm{T}$ cells $[49,50]$. IDO serves specific functions in microglia [51-
53], and IDO helps prevent EAE pathogenesis $[52,54]$. Thus nicotinic acid is particularly wellsuited for consideration in the treatment of multiple sclerosis.

Cannabis-derived natural products including delta-9tetrahydrocannabinol $(\triangle 9-\mathrm{THC})$ also have a long history of significantly delaying the onset of EAE [57-59] and immune suppression in general [60]. The oromucosal spray known as Sativex contains these natural products $(\Delta 9$ THC and cannabidiol) and is currently used for treating the neuropathic pain and spasticity associated with MS $[61,62]$. After the isolation of endogenous molecules that bind to the same G-protein coupled receptors as $\triangle 9$-THC, these "endocannabinoids" were also shown to provide relief from a viral-based animal model of MS, Theiler's Murine Encephalomyelitis Viral-immune demyelinating disease (TMEV-IDD; [63, 64]). However, only within the past several years has it become established that cannabinoids and endocannabinoids are in fact PPAR activators themselves $[65,66]$. Significantly, in some cases PPARs are required to mediate their actions. This includes the anandamide-mediated PPAR $\gamma$-dependent therapeutically desirable repression of interleukin-2 (IL-2 [67, 68]), a recently identified MS disease susceptibility gene [69]. Given their ability to function as endogenous PPAR agonists combined with their potential value in autoimmune demyelinating disease, anandamide and 2-arachidonoyl glycerol should be examined with respect to their effects on gene expression related to MS pathogenesis. 


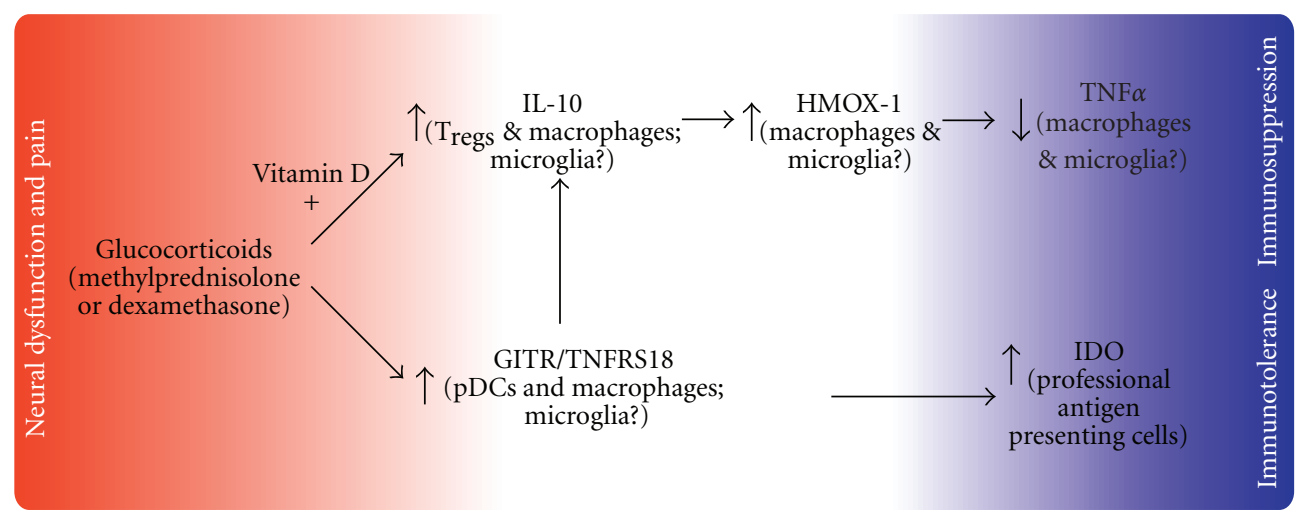

FIGURE 2: Glucocorticoids exert well-established relief from MS attacks, which last up to 30 days. Glucocorticoids exert immunoregulatory effects via transcriptional regulatory signaling in large part through GITR to IDO ([4, 5]) and IL-10 to HMOX-1 [8, 70, 71]). GITR activation is also known to lead to increased IL-10 production [72]. The representative glucocorticoid target genes of interest examined in this study with desirable effect are shown in bold. Multiple sclerosis patients are specifically lacking in CD46-stimulated IL-10 secretion and suffer from an over-proliferation of myelin autoreactive T cells.

\section{The Gold Standard of Transcriptomic Modeling for Treating Multiple Sclerosis, Glucocorticoid Target Genes: IDO \& IL-10}

Glucocorticoids comprise the most widely used drug class for providing rapid relief in acute attacks of MS. Thus, the immediate effect of glucocorticoids on target genes is the current gold standard for pharmacotherapeutic gene induction in MS treatment. Unfortunately, there is no reduction in relapse rate following glucocorticoid therapy, and relief is only temporary, lasting up to 30 days following a clinical attack. Given these limitations, there is an interest in sustained regulation of therapeutically beneficial glucocorticoid target genes by alternative approaches. Two recent studies suggest that both IL-10 and IDO likely mediate and determine the extent of glucocorticoid effects (Figure 2; IL$10[6]$, IDO $[4,5])$.

Recent studies in glucocorticoid-resistant asthma patients also implicate vitamin D as a factor in glucocorticoid effectiveness [6]. In these patients, the addition of dexamethasone does not cause an increase in IL-10 secretion from CD4+ cells. However, the addition of vitamin D3 with dexamethasone therapy in this population restores glucocorticoid-mediated induction of IL-10 [6]. The authors suggest that vitamin D can help restore glucocorticoid responsiveness. The combination of glucocorticoid with vitamin $\mathrm{D}$ is known to stimulate differentiation of CD4+ T cells to regulatory $\mathrm{T}$ cells (Treg) and causes substantial release of IL-10 (Figure 2, [73]). The role of vitamin D in preventing EAE models of MS is well established [74, 75], and there is a clear inverse correlation between vitamin D intake and MS occurrence (for a review see $[76,77]$ ). These observations suggest the possibility of providing glucocorticoid therapy in conjunction with vitamin D to extend therapeutic effects. Furthermore, the results illustrate the importance of ensuring that beneficial nuclear receptor agonists are supplied in adequate concentrations to prevent a rate limiting reduction in therapeutic benefit during acute MS attacks.
It should also be mentioned that vitamin $\mathrm{D}$ has recently been determined to be an inhibitor of PARP-1 [78]. PARP1 is the primary enzyme responsible for inflammationinduced depletion of cellular NAD (Figure 1). High-affinity PARP-1 inhibitors such as minocycline [79] have already proven beneficial in reducing clinical symptoms of MS in EAE models. Minocycline is currently being evaluated in the clinical treatment of MS [80-83]. PARP-1 appears to play an important role in MS pathogenesis.

Glucocorticoids strongly induce expression of TNFRSF18/glucocorticoid-induced TNFR-related (GITR) gene, which leads to induction of the enzyme controlling de novo NAD biosynthesis, indoleamine 2,3-dioxygenase (IDO). Most significantly the induction IDO activity is required for the full glucocorticoid anti-inflammatory effect $[4,5]$. Inhibition of IDO activity exacerbates experimental autoimmune encephalomyelitis $[52,54]$. All indications are that IDO induction may hinder autoimmune demyelination by starving autoreactive $\mathrm{T}$ cells of the essential amino acid tryptophan. Th1-derived cytokines tumor necrosis factor- $\alpha$ (TNF- $\alpha)$ or interferon- $\gamma$ (IFN- $\gamma$ ) induces transcription and activates IDO thus functioning as a timed feedback mechanism for limiting cytokine-stimulated proliferation of autoreactive T cells (for a review see [84]). The full potential for pharmacological exploitation of tryptophan depletion to promote immunotolerance in autoimmune disease remains largely unaddressed [85].

\section{Enzymatic Target Genes of Interest to MS}

Regulation of immune function ultimately requires some kind of enzymatic biochemistry. Three particularly desirable drug-mediated target gene inductions of interest in MS are IDO, mitochondrial superoxide dismutase (SOD2), and heme oxygenase-1 (HMOX-1). Increased expression of IDO [52, 54], SOD2 [86], or HMOX-1 [8] has been shown to exert protection against EAE pathogenesis. Thus, we are interested in small molecules that affect transcription of these genes. 
Here three respective paragraphs are devoted to discussing why transcriptional induction of these genes is expected to provide benefit in MS therapy.

The tryptophan depleting enzyme indoleamine 2,3dioxygenase (IDO) is also beneficial in EAE disease models of MS $[52,54]$, where IDO expression in microglia is tightly regulated by cytokines during inflammation [51-53]. In fact, IDO is centrally involved in nearly every examined autoimmune disease (for a review see [85]). As described above, IDO even appears central to the mechanism of glucocorticoid-mediated anti-inflammatory effects $[4,5]$. IDO mediates the most dramatic example of immunotolerance, fetal acceptance. Accordingly, IDO over-expression also prevents both transplant rejection [87] and the lethality of graft versus host disease [88]. Sometimes, the mechanism of enzyme action in the liquid immune system resembles microbial competition (for a review [84]). Professional antigen presenting cells (macrophages, dendritic cells, and microglia) use IDO activation to deplete local extracellular tryptophan. The effect is autotoleragenic through tryptophan starvation of tryptophan-sensitive circulating $\mathrm{T}$ cells. Professional antigen presenting cells exploit this primitive biochemical competition for nutrients to control $\mathrm{T}$ cell proliferation. The simplicity of the mechanism makes IDO particularly attractive for pharmacological intervention [85].

New studies reveal that increased heme oxygenase-1 (HMOX-1) can dramatically reverse paralytic EAE and prevent relapse [9]. This is in agreement with previous pharmacological analysis in EAE [89]. Absence of HMOX-1 enhances demyelination in EAE, while induction of HMOX1 with hemin or cobalt protoporphyrin can delay EAE onset. IL-10, a critical glucocorticoid target gene as described above, requires HMOX-1 activity to exert its immunosuppressive effects and is a known inducer of HMOX-1 [8]. Lastly, the end product of HMOX-1-catalyzed reaction, carbon monoxide, can itself mediate beneficial effects against EAE and is currently being considered as an MS therapeutic [9]. Heme oxygenase catalyzes the degradation of heme to produce iron, carbon monoxide, and biliverdin, the latter of which is subsequently degraded to produce the potent antioxidant bilirubin. HMOX-1 gene transcription is under the control of electrophile response elements that mediate extremely responsive transcriptional inducibility in response to oxidative stress ([90] and unpublished observations in zebrafish larvae). Consequently, HMOX-1 is often elevated in disease states as the body attempts to deal with oxidative pathosis.

A mere doubling of mitochondrial superoxide dismutase protein encoded by SOD2 via retroviral-mediated gene insertion strongly protects against EAE-mediated demyelination [86]. Increased oxidative stress, including decreases in superoxide dismutase, is a challenge in MS patients [91]. Amyotrophic lateral sclerosis (ALS) is a more severe CNS disease than MS, causing massive degeneration of motor neurons. SOD1 mutations are the only identified genetic link to familial amyotrophic lateral sclerosis [92]. Increased SOD2 is known to provide protection against mutated SOD1 neurotoxicity $[93,94]$. Superoxide dismutase serves essential functions as an endogenous free-radical scavenging antioxidizing enzyme. Loss of function of mitochondrial superoxide dismutase 2 (SOD2) results in perinatal lethality [95], while loss of cytosolic superoxide dismutase 1 (SOD1) results in hepatocellular carcinoma in mice [96]. Given that mitochondria are a well-established Achilles' heel on the way to cell death, it is worth considering that increased SOD2 expression may delay cell death due to SOD1 mutations. Modest increases in SOD2 are also known to increase lifespan in metazoans, where the pathway is now believed to involve reduction in insulin signaling [97].

\section{Common Pathways and Characteristics of Nonsteroidal Endogenous Antineuroinflammatory Molecules}

The endogenous nonglucocorticoid molecules shown to provide protection against MS or animal models thereof (EAE or TMEV-IDD) have a distinguishing common set of characteristics. By "endogenous," We are referring not only to those molecules which are synthesized endogenously but also the vitamins, which are endogenous in the sense that they must be present for survival regardless of the site of synthesis. This list includes nicotinamide [31], vitamin $\mathrm{D}[74,75]$, retinoic acid [24], 15d-PGJ 2 (12-16; [23$27]$ ), and the endocannabinoids [63, 64] (Figure 1). Natural product cannabinoids have also been shown to ameliorate EAE progression [98], thus further supporting the notion for a potential role for endocannabinoids in preventing autoimmune-mediated demyelination.

First, these molecules generally function as transcription factor ligands, which work through peroxisome proliferatoractivated receptor PPAR $\alpha$, PPAR $\gamma$, or vitamin D receptors, all of which must heterodimerize with retinoid $\mathrm{X}$ receptor-alpha (RXR) to mediate transcriptional effects (Figure 1). Second, these molecules are antiangiogenic. Vascular endothelial growth factor (VEGF) levels are elevated in virtually all known autoimmune diseases, and reduction of VEGF production tends to minimize autoimmune disease pathogenesis (for a review [99]). This is predicted since autoimmune diseases are diseases of hyperproliferation, and similar to solid tumors, they respond favorably when treated with antiangiogenics as discussed above. Third, many of the molecules that are effective against EAE also correct dyslipidemia, often raising high-density lipoprotein (HDL) while lowering triglycerides and low-density lipoprotein (LDL). Nicotinic acid/niacin provides the greatest boost of HDL levels of any known molecule, regulates angiogenesis, and activates PPAR $y$ indirectly by producing $15 \mathrm{~d}-\mathrm{PGJ}_{2}$ via the high-affinity nicotinic acid G-protein-coupled receptor HM74a/GPR109a located on professional antigen presenting cells $[28,100]$. However, nicotinic acid has not been examined in the context of MS therapy. Thus, additional consideration of nicotinic acid as a potential MS therapeutic is certainly warranted.

Virtually every endogenous molecule known to provide protection against animal models of MS is distinguished as also possessing antiangiogenic activity. This list of MS ameliorating antiangiogenic molecules includes vitamin D 
[101], 15d-PGD 2 [102, 103], retinoic acid (effects on EAE [104-107]; effects on angiogenesis [108-110]), and anandamide [111]. We have observed that NAD precursors exert positive angiogenic activities in the developing zebrafish (data not shown). This is likely due to the proven role of the NAD-responsive enzyme SIRT-1 in stimulating growth phase angiogenesis [112]. However, nicotinic acid seems likely to potentially possess antiangiogenic activities stemming from $\mathrm{PGD}_{2}$ production within professional antigen presenting cells which are expected to be anatomically localized to sites of inflammation. Thus, nicotinic acid may exert effects on angiogenesis independent of the developmental context, instead being dependent on the cellular localization of the GPR109a-expressing prostaglandin-producing professional APCs.

\section{Discussion}

Greater emphasis should be placed on exploring combinatorial approaches to treating autoimmune demyelinating disease. Numerous studies have detected increased therapeutic effectiveness in a variety of disease contexts when simultaneously activating both subunits of the PPAR:RXR $\alpha$ heterodimer (Figure 1). Most significantly, this combination of $15 \mathrm{~d}-\mathrm{PGJ}_{2}$ with 9 -cis retinoic acid exerts an additive effect in ameliorating EAE [24]. In vitro this mixture exerts a cooperative inhibition of microglial cell activation [113] and a cooperative antiproliferative effect on coronary artery smooth muscle cells [114]. The combination of PPAR $\gamma$ ligands with 9-cis retinoic acid increases the killing of multiple myeloma cells [115] and cooperatively suppresses expression of ADAMTS4/Aggregecanase-1 [116], a protein stimulated by IL-1 that erodes articular cartilage in arthritic disease. This latter effect alone strongly suggests that the combination of $15 \mathrm{~d}-\mathrm{PGJ}_{2}$ and 9 -cis retinoic acid may be particularly useful for the treatment of the autoimmune disease rheumatoid arthritis.

It seems most likely that additional activation of other nuclear receptors may exert a synergistic therapeutically beneficial effect in treating MS. For example, vitamin D or endocannabinoids may also exert cooperative effects. New studies indicate that both cannabinoid receptors $\mathrm{CB}_{1}$ and $\mathrm{CB}_{2}$ must be activated in order to stimulate myelination [117]. Extrapolation suggests that more than one molecule would be required for any potential recovery from MS neurodegeneration. Even glucocorticoids are not enough to prevent relapse rate. A teleost-based EAE model should be considered toward achieving higher throughput in an animal model for directly comparing the many small molecule permutations of potential drug combinations for their therapeutic value in treating MS.

Positron emission tomography studies performed in mice have shown that nicotinamide penetrates the mammalian blood-brain barrier [118]. High doses of oral nicotinic acid are well established in their ability to help treat the CNS disease schizophrenia [119-121]. Dramatic increases in NAD were detected in the spinal cord of mice subcutaneously injected with pharmacological doses of nicotinamide with concomitant profound protection against behavioral defects, demyelination, and death from EAE [31]. Thus drug delivery aspects and pharmacokinetics of oral nicotinic acid or nicotinamide for treating MS are not expected to be an issue.

Given that glucocorticoids such as methylprednisolone are universally accepted as the first approach for treating acute attacks of MS. These glucocorticoids may be considered as the current gold standard for attempts to model desirable ligand-induced transcriptomic effects to treat MS. Glucocorticoids work in large part through induction of IDO and IL10 , the latter of which exerts its effects in part via HMOX-1 induction [8]. Consistent with a critical role for these specific glucocorticoid-target genes in providing relief against MS, ectopic studies have revealed that small increases in gene expression of the enzymes HMOX-1 [9], IDO [52, 54], or the mitochondrial superoxide dismutase (SOD2; [86]) prevent or reverse autoimmune demyelination.

The endogenous PPAR ligand activators $15 \mathrm{~d}-\mathrm{PGJ}_{2}$ and anandamide prevent demyelination in animal models of MS. Nicotinic acid, while untested in EAE models, is unique because of its ability to stimulate production of prostaglandins $15 \mathrm{~d}-\mathrm{PGJ}_{2}$ and $\mathrm{PGE}_{2}$, the latter of which increases IDO expression [49, 50]. Additionally, pharmacological nicotinic acid by increasing NAD concentrations is expected to activate SIRT-1, which has a protective effect against neurodegeneration involving microglia [37, 122]. Experimentally, combinatorial activation of PPARs, retinoid $\mathrm{X}$ receptor, and/or vitamin $\mathrm{D}$ receptor generally provides additive benefit against EAE. A higher throughput teleost-based EAE model is needed to compare the various pharmacological permutations.

In summary, more emphasis should be placed on developing a nonsteroidal antineuroinflammatory cocktail for treating MS starting with pharmacological doses of nicotinic acid, $15 \mathrm{~d}-\mathrm{PGJ}_{2}$, nicotinamide, anandamide, vitamin $\mathrm{D}$, and 9-cis retinoic acid toward extending the time frame of MS therapeutic benefit provided by glucocorticoids while minimizing dangerous side effects. Studies performed using animal models of MS indicate that there are multiple potentially rate-limiting factors controlling immune-mediated demyelinating disease progression. The range of possible nutritional and biochemical deficiencies in the etiology of MS, which may adversely affect the healing process, is complex. Thus it would be most prudent to consider combinatorial approaches as a means for providing the most reliable therapeutic treatment of multiple sclerosis.

\section{Abbreviations}

15d-PGJ 2 : $\quad 15$-deoxy- $\Delta^{12,14}$-prostaglandin J (2)

2-AG: 2-arachidonoylglycerol

S9-THC: Delta-9-tetrahydrocannabinol

ALS: $\quad$ Amyotrophic lateral sclerosis

CBs: $\quad$ Cannabinoids

$\mathrm{CB}_{1}, \mathrm{CB}_{2}$ : Cannabinoid receptor 1 and 2

EAE: $\quad$ Experimental autoimmune encephalomyelitis

GITR: Glucocorticoid-induced TNFR-related gene/TNF receptor superfamily, member 18 ; TNFRS18 


$\begin{array}{ll}\text { HDL: } & \text { High-density lipoprotein } \\ \text { IDO: } & \text { Indoleamine 2,3-dioxygenase } \\ \text { IFN- } \gamma: & \text { Interferon gamma } \\ \text { IL-2Ra: } & \text { Interleukin } 2 \text { receptor alpha } \\ \text { LXR: } & \text { Liver X receptor } \\ \text { MOA: } & \text { Mechanism of action } \\ \text { NAD: } & \text { Nicotinamide adenine dinucleotide } \\ & \text { Professional antigen presenting cells } \\ \text { PAPC: } & \text { (microglia, dendritic cells, macrophages, and } \\ & \text { B cells) } \\ \text { PGC1 } \alpha: & \text { PPAR } \gamma \text { coactivator-1 } \\ \text { PGE }: & \text { Prostaglandin E2 } \\ \text { PPAR } \alpha \text { and } & \text { Peroxisome proliferator-activated receptor } \alpha \\ \text { PPAR } \gamma: & \text { and } \gamma \\ \text { ROS: } & \text { Reactive oxygen species } \\ \text { RXR: } & \text { Retinoid X receptor } \\ \text { TMEV-IDD: } & \text { Theiler's Murine Encephalomyelitis } \\ \text { Virus: } & \text { Induced Demyelinating Disease } \\ \text { Thl }_{\mathrm{h} l}: & \text { T helper cells } \\ \text { T }_{\text {reg }}: & \text { Regulatory T cells } \\ \text { TNF- } \alpha: & \text { Tumor necrosis factor alpha } \\ \text { VDR: } & \text { Vitamin D receptor } \\ & \end{array}$

\section{Acknowledgments}

The author is most grateful to Drs. Patricia Salazar, Carmen Wheatley, Ronald J. Jandacek, and Soumya C. Chari for critical reading and writing assistance. $\mathrm{He}$ is also especially appreciative for many scientific insights and discussion provided by Dr. Robert Melamede regarding the functions of endocannabinoids.

\section{References}

[1] A. Bitsch and W. Brück, "Differentiation of multiple sclerosis subtypes: implications for treatment," CNS Drugs, vol. 16, no. 6, pp. 405-418, 2002.

[2] J. H. Noseworthy, C. Lucchinetti, M. Rodriguez, and B. G. Weinshenker, "Multiple sclerosis," The New England Journal of Medicine, vol. 343, no. 13, pp. 938-952, 2000.

[3] D. Tischner and H. M. Reichardt, "Glucocorticoids in the control of neuroinflammation," Molecular and Cellular Endocrinology, vol. 275, no. 1-2, pp. 62-70, 2007.

[4] U. Grohmann, C. Volpi, F. Fallarino, et al., "Reverse signaling through GITR ligand enables dexamethasone to activate IDO in allergy," Nature Medicine, vol. 13, no. 5, pp. 579-586, 2007.

[5] P. Puccetti and U. Grohmann, "IDO and regulatory T cells: a role for reverse signalling and non-canonical NF- $\kappa \mathrm{B}$ activation," Nature Reviews Immunology, vol. 7, no. 10, pp. 817-823, 2007.

[6] E. Xystrakis, S. Kusumakar, S. Boswell, et al., "Reversing the defective induction of IL-10-secreting regulatory T cells in glucocorticoid-resistant asthma patients," The Journal of Clinical Investigation, vol. 116, no. 1, pp. 146-155, 2006.

[7] B.-G. Xiao, X. Liu, and H. Link, "Antigen-specific T cell functions are suppressed over the estrogen-dendritic cellindoleamine 2,3-dioxygenase axis," Steroids, vol. 69, no. 10, pp. 653-659, 2004.
[8] T.-S. Lee and L.-Y. Chau, "Heme oxygenase-1 mediates the anti-inflammatory effect of interleukin-10 in mice," Nature Medicine, vol. 8, no. 3, pp. 240-246, 2002.

[9] Â. A. Chora, P. Fontoura, A. Cunha, et al., "Heme oxygenase1 and carbon monoxide suppress autoimmune neuroinflammation," The Journal of Clinical Investigation, vol. 117, no. 2, pp. 438-447, 2007.

[10] J. N. H. Stern, D. B. Keskin, H. Zhang, H. Lv, Z. Kato, and J. L. Strominger, "Amino acid copolymer-specific IL-10-secreting regulatory $\mathrm{T}$ cells that ameliorate autoimmune diseases in mice," Proceedings of the National Academy of Sciences of the United States of America, vol. 105, no. 13, pp. 5172-5176, 2008.

[11] E. R. Pfefferkorn, "Interferon $\gamma$ blocks the growth of Toxoplasma gondii in human fibroblasts by inducing the host cells to degrade tryptophan," Proceedings of the National Academy of Sciences of the United States of America, vol. 81, no. 3, pp. 908-912, 1984.

[12] G. I. Byrne, L. K. Lehmann, and G. J. Landry, "Induction of tryptophan catabolism is the mechanism for gammainterferon-mediated inhibition of intracellular Chlamydia psittaci replication in T24 cells," Infection and Immunity, vol. 53, no. 2, pp. 347-351, 1986.

[13] C. R. MacKenzie, U. Hadding, and W. Däubener, "Interferon$\gamma$-induced activation of indoleamine 2,3-dioxygenase in cord blood monocyte-derived macrophages inhibits the growth of group B streptococci," Journal of Infectious Diseases, vol. 178, no. 3, pp. 875-878, 1998.

[14] L. A. Sanni, S. R. Thomas, B. N. Tattam, et al., "Dramatic changes in oxidative tryptophan metabolism along the kynurenine pathway in experimental cerebral and noncerebral malaria," American Journal of Pathology, vol. 152, no. 2, pp. 611-619, 1998.

[15] B. Bodaghi, O. Goureau, D. Zipeto, L. Laurent, J.-L. Virelizier, and S. Michelson, "Role of IFN- $\gamma$-induced indoleamine 2,3 dioxygenase and inducible nitric oxide synthase in the replication of human cytomegalovirus in retinal pigment epithelial cells," The Journal of Immunology, vol. 162, no. 2, pp. 957-964, 1999.

[16] N. M. Silva, C. V. Rodrigues, M. M. Santoro, L. F. L. Reis, J. I. Alvarez-Leite, and R. T. Gazzinelli, "Expression of indoleamine 2,3-dioxygenase, tryptophan degradation, and kynurenine formation during in vivo infection with Toxoplasma gondii: induction by endogenous gamma interferon and requirement of interferon regulatory factor 1," Infection and Immunity, vol. 70, no. 2, pp. 859-868, 2002.

[17] O. Adams, K. Besken, C. Oberdörfer, C. R. MacKenzie, D. Rüßing, and W. Däubener, "Inhibition of human herpes simplex virus type 2 by interferon $\gamma$ and tumor necrosis factor $\alpha$ is mediated by indoleamine 2,3-dioxygenase," Microbes and Infection, vol. 6, no. 9, pp. 806-812, 2004.

[18] O. Adams, K. Besken, C. Oberdörfer, C. R. MacKenzie, O. Takikawa, and W. Däubener, "Role of indoleamine-2,3dioxygenase in alpha/beta and gamma interferon-mediated antiviral effects against herpes simplex virus infections," Journal of Virology, vol. 78, no. 5, pp. 2632-2636, 2004.

[19] E. M. Wallack and R. Callon, "Liver injury associated with the $\beta$-interferons for MS," Neurology, vol. 63, no. 6, pp. 11421143, 2004.

[20] O. Stüve, J. L. Bennett, B. Hemmer, et al., "Pharmacological treatment of early multiple sclerosis," Drugs, vol. 68, no. 1, pp. 73-83, 2008. 
[21] A. G. Baxter, "The origin and application of experimental autoimmune encephalomyelitis," Nature Reviews Immunology, vol. 7, no. 11, pp. 904-912, 2007.

[22] L. Steinman and S. S. Zamvil, "How to successfully apply animal studies in experimental allergic encephalomyelitis to research on multiple sclerosis," Annals of Neurology, vol. 60, no. 1, pp. 12-21, 2006.

[23] A. Diab, C. Deng, J. D. Smith, et al., "Peroxisome proliferatoractivated receptor- $\gamma$ agonist 15 -deoxy- $\Delta^{12,14}$-prostaglandin $\mathrm{J}_{2}$ ameliorates experimental autoimmune encephalomyelitis," The Journal of Immunology, vol. 168, no. 5, pp. 2508-2515, 2002.

[24] A. Diab, R. Z. Hussain, A. E. Lovett-Racke, J. A. Chavis, P. D. Drew, and M. K. Racke, "Ligands for the peroxisome proliferator-activated receptor- $\gamma$ and the retinoid $\mathrm{X}$ receptor exert additive anti-inflammatory effects on experimental autoimmune encephalomyelitis," Journal of Neuroimmunology, vol. 148, no. 1-2, pp. 116-126, 2004.

[25] S. A. Kliewer, J. M. Lenhard, T. M. Willson, I. Patel, D. C. Morris, and J. M. Lehmann, "A prostaglandin $\mathrm{J}_{2}$ metabolite binds peroxisome proliferator-activated receptor $\gamma$ and promotes adipocyte differentiation," Cell, vol. 83, no. 5, pp. 813-819, 1995.

[26] H. P. Raikwar, G. Muthian, J. Rajasingh, C. N. Johnson, and J. J. Bright, "PPAR $y$ antagonists reverse the inhibition of neural antigen-specific $\mathrm{Th}_{1}$ response and experimental allergic encephalomyelitis by Ciglitazone and 15-deoxy$\Delta^{12,14}$-prostaglandin $\mathrm{J}_{2}$," Journal of Neuroimmunology, vol. 178, no. 1-2, pp. 76-86, 2006.

[27] R. K. Semple, V. K. K. Chatterjee, and S. O'Rahilly, "PPAR $\gamma$ and human metabolic disease," The Journal of Clinical Investigation, vol. 116, no. 3, pp. 581-589, 2006.

[28] H. J. Knowles, R. te Poole, P. Workman, and A. L. Harris, "Niacin induces PPAR $y$ expression and transcriptional activation in macrophages via HM74 and HM74a-mediated induction of prostaglandin synthesis pathways," Biochemical Pharmacology, vol. 71, no. 5, pp. 646-656, 2006.

[29] T. Rubic, M. Trottmann, and R. L. Lorenz, "Stimulation of CD36 and the key effector of reverse cholesterol transport ATP-binding cassette A1 in monocytoid cells by niacin," Biochemical Pharmacology, vol. 67, no. 3, pp. 411-419, 2004.

[30] L. A. Carlson, "Nicotinic acid: the broad-spectrum lipid drug. A 50th anniversary review," Journal of Internal Medicine, vol. 258, no. 2, pp. 94-114, 2005.

[31] S. Kaneko, J. Wang, M. Kaneko, et al., "Protecting axonal degeneration by increasing nicotinamide adenine dinucleotide levels in experimental autoimmune encephalomyelitis models," The Journal of Neuroscience, vol. 26, no. 38, pp. 9794-9804, 2006.

[32] L. M. Henderson and C. J. Gross, "Metabolism of niacin and niacinamide in perfused rat intestine," Journal of Nutrition, vol. 109, no. 4, pp. 654-662, 1979.

[33] V. Micheli, H. A. Simmonds, S. Sestini, and C. Ricci, "Importance of nicotinamide as an NAD precursor in the human erythrocyte," Archives of Biochemistry and Biophysics, vol. 283, no. 1, pp. 40-45, 1990.

[34] R. S. Grant and V. Kapoor, "Murine glial cells regenerate NAD, after peroxide-induced depletion, using either nicotinic acid, nicotinamide, or quinolinic acid as substrates," Journal of Neurochemistry, vol. 70, no. 4, pp. 1759-1763, 1998.
[35] Y. Sasaki, T. Araki, and J. Milbrandt, "Stimulation of nicotinamide adenine dinucleotide biosynthetic pathways delays axonal degeneration after axotomy," The Journal of Neuroscience, vol. 26, no. 33, pp. 8484-8491, 2006.

[36] R. Adalbert, T. H. Gillingwater, J. E. Haley, et al., "A rat model of slow Wallerian degeneration $\left(W l d^{S}\right)$ with improved preservation of neuromuscular synapses," European Journal of Neuroscience, vol. 21, no. 1, pp. 271-277, 2005.

[37] T. Araki, Y. Sasaki, and J. Milbrandt, "Increased nuclear NAD biosynthesis and SIRT1 activation prevent axonal degeneration," Science, vol. 305, no. 5686, pp. 1010-1013, 2004.

[38] N. A. Bishop and L. Guarente, "Genetic links between diet and lifespan: shared mechanisms from yeast to humans," Nature Reviews Genetics, vol. 8, no. 11, pp. 835-844, 2007.

[39] X. Li, S. Zhang, G. Blander, J. G. Tse, M. Krieger, and L. Guarente, "SIRT1 deacetylates and positively regulates the nuclear receptor LXR," Molecular Cell, vol. 28, no. 1, pp. 91106, 2007.

[40] B. Beirowski, E. Babetto, J. Gilley, et al., "Non-nuclear $W l d^{S}$ determines its neuroprotective efficacy for axons and synapses in vivo," The Journal of Neuroscience, vol. 29, no. 3, pp. 653-668, 2009.

[41] G. C. Brown, "Mechanisms of inflammatory neurodegeneration: iNOS and NADPH oxidase," Biochemical Society Transactions, vol. 35, no. 5, pp. 1119-1121, 2007.

[42] W. T. Penberthy and I. Tsunoda, "The importance of NAD in multiple sclerosis," Current Pharmaceutical Design, vol. 15, no. 1, pp. 64-99, 2009.

[43] M. F. McCarty and A. L. Russell, "Niacinamide therapy for osteoarthritis-does it inhibit nitric oxide synthase induction by interleukin-1 in chondrocytes?" Medical Hypotheses, vol. 53, no. 4, pp. 350-360, 1999.

[44] D. A. Powers, L. Hereford, T. Cole, et al., "Electroporation: a method for transferring genes into the gametes of zebrafish (Brachydanio rerio), channel catfish (Ictalurus punctatus), and common carp (Cyprinus carpio)," Molecular Marine Biology and Biotechnology, vol. 1, no. 4-5, pp. 301-308, 1992.

[45] B. Eklund, L. Kaijser, J. Nowak, and A. Wennmalm, "Prostaglandins contribute to the vasodilation induced by nicotinic acid," Prostaglandins, vol. 17, no. 6, pp. 821-830, 1979.

[46] J. D. Morrow, W. G. Parsons III, and L. J. Roberts II, "Release of markedly increased quantities of prostaglandin D2 in vivo in humans following the administration of nicotinic acid," Prostaglandins, vol. 38, no. 2, pp. 263-274, 1989.

[47] A. G. Olsson, L. A. Carlson, E. Anggard, and G. Ciabattoni, "Prostacyclin production augmented in the short term by nicotinic acid," The Lancet, vol. 2, no. 8349, pp. 565-566, 1983.

[48] Z. Benyó, A. Gille, C. L. Bennett, B. E. Clausen, and S. Offermanns, "Nicotinic acid-induced flushing is mediated by activation of epidermal Langerhans cells," Molecular Pharmacology, vol. 70, no. 6, pp. 1844-1849, 2006.

[49] D. Braun, R. S. Longman, and M. L. Albert, "A two-step induction of indoleamine 2,3 dioxygenase (IDO) activity during dendritic-cell maturation," Blood, vol. 106, no. 7, pp. 2375-2381, 2005.

[50] M. S. von Bergwelt-Baildon, A. Popov, T. Saric, et al., "CD25 and indoleamine 2,3-dioxygenase are up-regulated by prostaglandin E2 and expressed by tumor-associated dendritic cells in vivo: additional mechanisms of T-cell inhibition," Blood, vol. 108, no. 1, pp. 228-237, 2006. 
[51] G. J. Guillemin, G. Smythe, O. Takikawa, and B. J. Brew, "Expression of indoleamine 2,3-dioxygenase and production of quinolinic acid by human microglia, astrocytes, and neurons," GLIA, vol. 49, no. 1, pp. 15-23, 2005.

[52] E. Kwidzinski, J. Bunse, O. Aktas, et al., "Indolamine 2,3dioxygenase is expressed in the CNS and down-regulates autoimmune inflammation," The FASEB Journal, vol. 19, no. 10, pp. 1347-1349, 2005.

[53] E. Kwidzinski, J. Bunse, A. D. Kovac, et al., "IDO (indolamine 2,3-dioxygenase) expression and function in the CNS," Advances in Experimental Medicine and Biology, vol. 527, pp. 113-118, 2003.

[54] K. Sakurai, J.-P. Zou, J. R. Tschetter, J. M. Ward, and G. M. Shearer, "Effect of indoleamine 2,3-dioxygenase on induction of experimental autoimmune encephalomyelitis," Journal of Neuroimmunology, vol. 129, no. 1-2, pp. 186-196, 2002.

[55] S. Offermanns, "The nicotinic acid receptor GPR109A (HM74A or PUMA-G) as a new therapeutic target," Trends in Pharmacological Sciences, vol. 27, no. 7, pp. 384-390, 2006.

[56] V. S. Kamanna and M. L. Kashyap, "Nicotinic acid (niacin) receptor agonists: will they be useful therapeutic agents?" The American Journal of Cardiology, vol. 100, no. 11, supplement 1, pp. S53-S61, 2007.

[57] M. Fujiwara and N. Egashira, "New perspectives in the studies on endocannabinoid and cannabis: abnormal behaviors associate with CB1 cannabinoid receptor and development of therapeutic application," Journal of Pharmacological Sciences, vol. 96, no. 4, pp. 362-366, 2004.

[58] W. D. Lyman, J. R. Sonett, C. F. Brosnan, R. Elkin, and M. B. Bornstein, " $\Delta 9$-tetrahydrocannabinol: a novel treatment for experimental autoimmune encephalomyelitis," Journal of Neuroimmunology, vol. 23, no. 1, pp. 73-81, 1989.

[59] G. Pryce, Z. Ahmed, D. J. R. Hankey, et al., "Cannabinoids inhibit neurodegeneration in models of multiple sclerosis," Brain, vol. 126, no. 10, pp. 2191-2202, 2003.

[60] Y. K. Luthra, H. J. Esber, D. M. Lariviere, and H. Rosenkrantz, "Assessment of tolerance to immunosuppressive activity of $\Delta$ 9-tetrahydrocannabinol in rats," Journal of Immunopharmacology, vol. 2, no. 2, pp. 245-256, 1980.

[61] T. J. Nurmikko, M. G. Serpell, B. Hoggart, P. J. Toomey, B. J. Morlion, and D. Haines, "Sativex successfully treats neuropathic pain characterised by allodynia: a randomised, double-blind, placebo-controlled clinical trial," Pain, vol. 133, no. 1-3, pp. 210-220, 2007.

[62] P. F. Smith, "Symptomatic treatment of multiple sclerosis using cannabinoids: recent advances," Expert Review of Neurotherapeutics, vol. 7, no. 9, pp. 1157-1163, 2007.

[63] L. Mestre, F. Correa, A. Arévalo-Martín, et al., "Pharmacological modulation of the endocannabinoid system in a viral model of multiple sclerosis," Journal of Neurochemistry, vol. 92, no. 6, pp. 1327-1339, 2005.

[64] S. Ortega-Gutiérrez, E. Molina-Holgado, Á. Árevalo-Martín, et al., "Activation of the endocannabinoid system as therapeutic approach in a murine model of multiple sclerosis," The FASEB Journal, vol. 19, no. 10, pp. 1338-1340, 2005.

[65] G. D’Agostino, G. La Rana, R. Russo, et al., "Acute intracerebroventricular administration of palmitoylethanolamide, an endogenous peroxisome proliferator-activated receptor$\alpha$ agonist, modulates carrageenan-induced paw edema in mice," Journal of Pharmacology and Experimental Therapeutics, vol. 322, no. 3, pp. 1137-1143, 2007.
[66] S. E. O'Sullivan, "Cannabinoids go nuclear: evidence for activation of peroxisome proliferator-activated receptors," British Journal of Pharmacology, vol. 152, no. 5, pp. 576-582, 2007.

[67] C. E. Rockwell and N. E. Kaminski, "A cyclooxygenase metabolite of anandamide causes inhibition of interleukin2 secretion in murine splenocytes," Journal of Pharmacology and Experimental Therapeutics, vol. 311, no. 2, pp. 683-690, 2004.

[68] C. E. Rockwell, N. T. Snider, J. T. Thompson, J. P. Vanden Heuvel, and N. E. Kaminski, "Interleukin-2 suppression by 2 -arachidonyl glycerol is mediated through peroxisome proliferator-activated receptor $\gamma$ independently of cannabinoid receptors 1 and 2," Molecular Pharmacology, vol. 70, no. 1, pp. 101-111, 2006.

[69] D. A. Hafler, A. Compston, S. Sawcer, et al., "Risk alleles for multiple sclerosis identified by a genomewide study," The New England Journal of Medicine, vol. 357, no. 9, pp. 851-862, 2007.

[70] Y. Drechsler, A. Dolganiuc, O. Norkina, et al., "Heme oxygena-1 mediates the anti-inflammatory effects of acute alcohol on IL-10 induction involving p38 MAPK activation in monocytes," The Journal of Immunology, vol. 177, no. 4, pp. 2592-2600, 2006.

[71] G. A. Ricchetti, L. M. Williams, and B. M. J. Foxwell, "Heme oxygenase 1 expression induced by IL-10 requires STAT-3 and phosphoinositol-3 kinase and is inhibited by lipopolysaccharide," Journal of Leukocyte Biology, vol. 76, no. 3, pp. 719-726, 2004.

[72] P. Zhou, L. L'Italien, D. Hodges, and X. M. Schebye, "Pivotal roles of $\mathrm{CD}^{+}$effector $\mathrm{T}$ cells in mediating agonistic antiGITR mAb-induced-immune activation and tumor immunity in CT26 tumors," The Journal of Immunology, vol. 179, no. 11, pp. 7365-7375, 2007.

[73] F. J. Barrat, D. J. Cua, A. Boonstra, et al., "In vitro generation of interleukin 10-producing regulatory $\mathrm{CD}^{+} \mathrm{T}$ cells is induced by immunosuppressive drugs and inhibited by $\mathrm{T}$ helper type 1 (Th1)- and Th2-inducing cytokines," The Journal of Experimental Medicine, vol. 195, no. 5, pp. 603616, 2002.

[74] M. T. Cantorna, "Vitamin D and its role in immunology: multiple sclerosis, and inflammatory bowel disease," Progress in Biophysics and Molecular Biology, vol. 92, no. 1, pp. 60-64, 2006.

[75] M. T. Cantorna, C. E. Hayes, and H. F. DeLuca, "1,25dihydroxyvitamin $\mathrm{D}_{3}$ reversibly blocks the progression of relapsing encephalomyelitis, a model of multiple sclerosis," Proceedings of the National Academy of Sciences of the United States of America, vol. 93, no. 15, pp. 7861-7864, 1996.

[76] I. A. F. van der Mei, A.-L. Ponsonby, L. Blizzard, and T. Dwyer, "Regional variation in multiple sclerosis prevalence in Australia and its association with ambient ultraviolet radiation," Neuroepidemiology, vol. 20, no. 3, pp. 168-174, 2001.

[77] S. J. Brown, "The role of vitamin D in multiple sclerosis," Annals of Pharmacotherapy, vol. 40, no. 6, pp. 1158-1161, 2006.

[78] J. G. Mabley, R. Wallace, P. Pacher, K. Murphy, and C. Szabó, "Inhibition of poly(adenosine diphosphate-ribose) polymerase by the active form of vitamin D," International Journal of Molecular Medicine, vol. 19, no. 6, pp. 947-952, 2007. 
[79] C. C. Alano, T. M. Kauppinen, A. V. Valls, and R. A. Swanson, "Minocycline inhibits poly(ADP-ribose) polymerase-1 at nanomolar concentrations," Proceedings of the National Academy of Sciences of the United States of America, vol. 103, no. 25, pp. 9685-9690, 2006.

[80] T. M. Kauppinen, "Multiple roles for poly(ADP-ribose)polymerase-1 in neurological disease," Neurochemistry International, vol. 50, no. 7-8, pp. 954-958, 2007.

[81] I. Luccarini, C. Ballerini, T. Biagioli, et al., "Combined treatment with atorvastatin and minocycline suppresses severity of EAE," Experimental Neurology, vol. 211, no. 1, pp. 214-226, 2008.

[82] M. Ruggieri, C. Pica, A. Lia, et al., "Combination treatment of Glatiramer Acetate and Minocycline affects phenotype expression of blood monocyte-derived dendritic cells in Multiple Sclerosis patients," Journal of Neuroimmunology, vol. 197, no. 2, pp. 140-146, 2008.

[83] R. K. Zabad, L. M. Metz, T. R. Todoruk, et al., "The clinical response to minocycline in multiple sclerosis is accompanied by beneficial immune changes: a pilot study," Multiple Sclerosis, vol. 13, no. 4, pp. 517-526, 2007.

[84] A. L. Mellor and D. H. Munn, "IDO expression by dendritic cells: tolerance and tryptophan catabolism," Nature Reviews Immunology, vol. 4, no. 10, pp. 762-774, 2004.

[85] W. T. Penberthy, "Pharmacological targeting of IDOmediated tolerance for treating autoimmune disease," Current Drug Metabolism, vol. 8, no. 3, pp. 245-266, 2007.

[86] X. Qi, A. S. Lewin, L. Sun, W. W. Hauswirth, and J. Guy, "Suppression of mitochondrial oxidative stress provides long-term neuroprotection in experimental optic neuritis," Investigative Ophthalmology and Visual Science, vol. 48, no. 2, pp. 681-691, 2007.

[87] A. M. Alexander, M. Crawford, S. Bertera, et al., "Indoleamine 2,3-dioxygenase expression in transplanted NOD Islets prolongs graft survival after adoptive transfer of diabetogenic splenocytes," Diabetes, vol. 51, no. 2, pp. 356-365, 2002.

[88] L. K. Jasperson, C. Bucher, A. Panoskaltsis-Mortari, et al., "Indoleamine 2,3-dioxygenase is a critical regulator of acute graft-versus-host disease lethality," Blood, vol. 111, no. 6, pp. 3257-3265, 2008.

[89] Y. Liu, B. Zhu, L. Luo, P. Li, D. W. Paty, and M. S. Cynader, "Heme oxygenase-1 plays an important protective role in experimental autoimmune encephalomyelitis," NeuroReport, vol. 12, no. 9, pp. 1841-1845, 2001.

[90] E. D. Owuor and A.-N. T. Kong, "Antioxidants and oxidants regulated signal transduction pathways," Biochemical Pharmacology, vol. 64, no. 5-6, pp. 765-770, 2002.

[91] C. Syburra and S. Passi, "Oxidative stress in patients with multiple sclerosis," Ukrainskii Biokhimicheskii Zhurnal, vol. 71, no. 3, pp. 112-115, 1999.

[92] F. Gros-Louis, C. Gaspar, and G. A. Rouleau, "Genetics of familial and sporadic amyotrophic lateral sclerosis," Biochimica et Biophysica Acta, vol. 1762, no. 11-12, pp. 956-972, 2006.

[93] O. A. Andreassen, R. J. Ferrante, P. Klivenyi, et al., "Partial deficiency of manganese superoxide dismutase exacerbates a transgenic mouse model of amyotrophic lateral sclerosis," Annals of Neurology, vol. 47, no. 4, pp. 447-455, 2000.

[94] M. C. Zimmerman, L. W. Oberley, and S. W. Flanagan, "Mutant SOD1-induced neuronal toxicity is mediated by increased mitochondrial superoxide levels," Journal of Neurochemistry, vol. 102, no. 3, pp. 609-618, 2007.
[95] Y. Li, T.-T. Huang, E. J. Carlson, et al., "Dilated cardiomyopathy and neonatal lethality in mutant mice lacking manganese superoxide dismutase," Nature Genetics, vol. 11, no. 4, pp. 376-381, 1995.

[96] S. Elchuri, T. D. Oberley, W. Qi, et al., "CuZnSOD deficiency leads to persistent and widespread oxidative damage and hepatocarcinogenesis later in life," Oncogene, vol. 24, no. 3, pp. 367-380, 2005.

[97] C. Curtis, G. N. Landis, D. Folk, et al., "Transcriptional profiling of MnSOD-mediated lifespan extension in Drosophila reveals a species-general network of aging and metabolic genes," Genome Biology, vol. 8, no. 12, article R262, pp. 1-27, 2007.

[98] K. Maresz, G. Pryce, E. D. Ponomarev, et al., "Direct suppression of CNS autoimmune inflammation via the cannabinoid receptor $\mathrm{CB}_{1}$ on neurons and $\mathrm{CB}_{2}$ on autoreactive T cells," Nature Medicine, vol. 13, no. 4, pp. 492-497, 2007.

[99] J. F. Carvalho, M. Blank, and Y. Shoenfeld, "Vascular endothelial growth factor (VEGF) in autoimmune diseases," Journal of Clinical Immunology, vol. 27, no. 3, pp. 246-256, 2007.

[100] Y. Tang, L. Zhou, J. W. Gunnet, P. G. Wines, E. V. Cryan, and K. T. Demarest, "Enhancement of arachidonic acid signaling pathway by nicotinic acid receptor HM74A," Biochemical and Biophysical Research Communications, vol. 345, no. 1, pp. 2937, 2006.

[101] B.-Y. Bao, J. Yao, and Y.-F. Lee, “ $1 \alpha$, 25-dihydroxyvitamin D3 suppresses interleukin-8-mediated prostate cancer cell angiogenesis," Carcinogenesis, vol. 27, no. 9, pp. 1883-1893, 2006.

[102] V. Chintalgattu, G. S. Harris, S. M. Akula, and L. C. Katwa, "PPAR- $\gamma$ agonists induce the expression of VEGF and its receptors in cultured cardiac myofibroblasts," Cardiovascular Research, vol. 74, no. 1, pp. 140-150, 2007.

[103] X. Xin, S. Yang, J. Kowalski, and M. E. Gerritsen, "Peroxisome proliferator-activated receptor $\gamma$ ligands are potent inhibitors of angiogenesis in vitro and in vivo," Journal of Biological Chemistry, vol. 274, no. 13, pp. 9116-9121, 1999.

[104] L. Massacesi, A. L. Abbamondi, C. Giorgi, F. Sarlo, F. Lolli, and L. Amaducci, "Suppression of experimental allergic encephalomyelitis by retinoic acid," Journal of the Neurological Sciences, vol. 80, no. 1, pp. 55-64, 1987.

[105] L. Massacesi, A. L. Abbamondi, F. Sarlo, and L. Amaducci, "The control of experimental allergic encephalomyelitis with retinoic acid. Further studies," Rivista di Neurologia, vol. 57, no. 3, pp. 166-169, 1987.

[106] M. K. Racke, D. Burnett, S.-H. Pak, et al., "Retinoid treatment of experimental allergic encephalomyelitis: IL-4 production correlates with improved disease course," Journal of Immunology, vol. 154, no. 1, pp. 450-458, 1995.

[107] J. Xu, P. D. Storer, J. A. Chavis, M. K. Racke, and P. D. Drew, "Agonists for the peroxisome proliferator-activated receptor$\alpha$ and the retinoid $\mathrm{X}$ receptor inhibit inflammatory responses of microglia," Journal of Neuroscience Research, vol. 81, no. 3, pp. 403-411, 2005.

[108] E. S. Arsenou, E. P. Papadimitriou, E. Kliafa, M. Hountala, and S. S. Nikolaropoulos, "Effects of retinoic acid steroidal analogs on human leukemic HL60 cell proliferation in vitro and on angiogenesis in vivo," Anti-Cancer Drugs, vol. 16, no. 2, pp. 151-158, 2005.

[109] S. Hoffmann, A. Rockenstein, A. Ramaswamy, et al., "Retinoic acid inhibits angiogenesis and tumor growth of thyroid cancer cells," Molecular and Cellular Endocrinology, vol. 264, no. 1-2, pp. 74-81, 2007. 
[110] M. K. Tee, J.-L. Vigne, and R. N. Taylor, "All-trans retinoic acid inhibits vascular endothelial growth factor expression in a cell model of neutrophil activation," Endocrinology, vol. 147, no. 3, pp. 1264-1270, 2006.

[111] S. Pisanti, C. Borselli, O. Oliviero, C. Laezza, P. Gazzerro, and M. Bifulco, "Antiangiogenic activity of the endocannabinoid anandamide: correlation to its tumor-suppressor efficacy," Journal of Cellular Physiology, vol. 211, no. 2, pp. 495-503, 2007.

[112] M. Potente, L. Ghaeni, D. Baldessari, et al., "SIRT1 controls endothelial angiogenic functions during vascular growth," Genes and Development, vol. 21, no. 20, pp. 2644-2658, 2007.

[113] P. D. Drew, P. D. Storer, J. Xu, and J. A. Chavis, "Hormone regulation of microglial cell activation: relevance to multiple sclerosis," Brain Research Reviews, vol. 48, no. 2, pp. 322-327, 2005.

[114] S. Benson, S. Padmanabhan, T. W. Kurtz, and H. A. Pershadsingh, "Ligands for the peroxisome proliferatoractivated receptor- $\gamma$ and the retinoid $\mathrm{X}$ receptor- $\alpha$ exert synergistic antiproliferative effects on human coronary artery smooth muscle cells," Molecular Cell Biology Research Communications, vol. 3, no. 3, pp. 159-164, 2000.

[115] D. M. Ray, S. H. Bernstein, and R. P. Phipps, "Human multiple myeloma cells express peroxisome proliferatoractivated receptor $\gamma$ and undergo apoptosis upon exposure to PPAR $y$ ligands," Clinical Immunology, vol. 113, no. 2, pp. 203-213, 2004.

[116] J. R. Worley, M. D. Baugh, D. A. Hughes, et al., "Metalloproteinase expression in PMA-stimulated THP-1 cells: effects of peroxisome proliferator-activated receptor- $\gamma(\operatorname{PPAR} \gamma)$ agonists and 9-cis-retinoic acid," Journal of Biological Chemistry, vol. 278, no. 51, pp. 51340-51346, 2003.

[117] A. Arévalo-Martín, D. García-Ovejero, A. Rubio-Araiz, O. Gómez, F. Molina-Holgado, and E. Molina-Holgado, "Cannabinoids modulate Olig2 and polysialylated neural cell adhesion molecule expression in the subventricular zone of post-natal rats through cannabinoid receptor 1 and cannabinoid receptor 2," European Journal of Neuroscience, vol. 26, no. 6, pp. 1548-1559, 2007.

[118] L. V. Hankes, H. H. Coenen, E. Rota, et al., "Effect of Huntington's and Alzheimer's diseases on the transport of nicotinic acid or nicotinamide across the human blood-brain barrier," Advances in Experimental Medicine and Biology, vol. 294, pp. 675-678, 1991.

[119] A. Hoffer, "Treatment of arthritis by nicotinic acid and nicotinamide," Canadian Medical Association Journal, vol. 81, no. 4, pp. 235-238, 1959.

[120] A. Hoffer, Adventures in Psychiatry: The Scientific Memoirs of Dr. Abram Hoffer, KOS Publishing, Alton, Ont, USA, 2005.

[121] H. Osmond and A. Hoffer, "Massive niacin treatment in schizophrenia. Review of a nine-year study," The Lancet, vol. 279, no. 7224, pp. 316-320, 1962.

[122] J. Chen, Y. Zhou, S. Mueller-Steiner, et al., "SIRT1 protects against microglia-dependent amyloid- $\beta$ toxicity through inhibiting NF- $\kappa \mathrm{B}$ signaling," The Journal of Biological Chemistry, vol. 280, no. 48, pp. 40364-40374, 2005. 


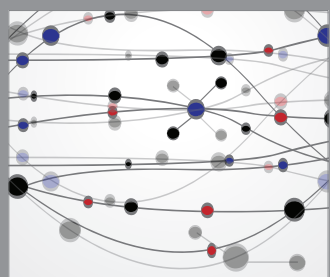

The Scientific World Journal
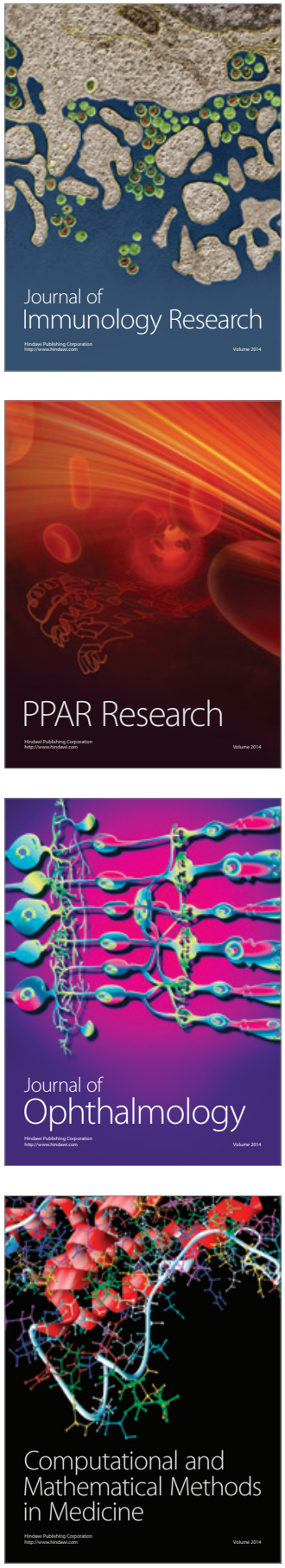

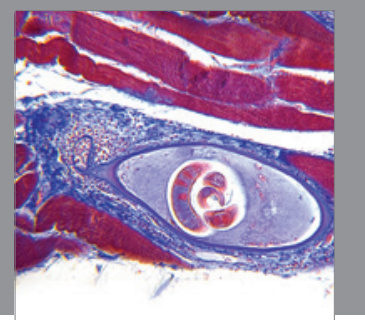

Gastroenterology

Research and Practice
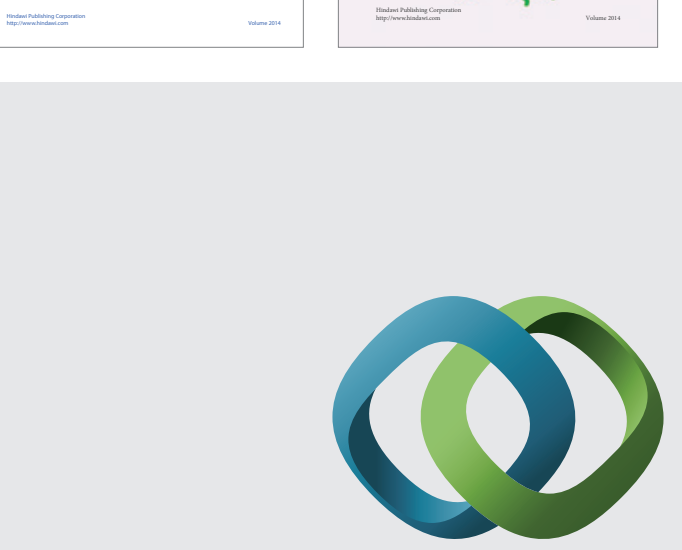

\section{Hindawi}

Submit your manuscripts at

http://www.hindawi.com
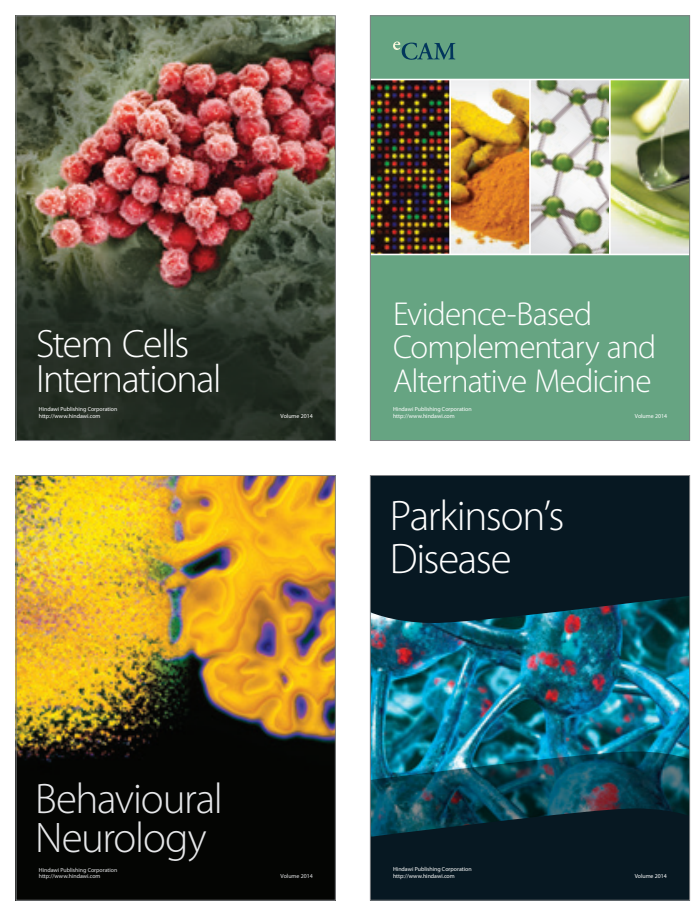

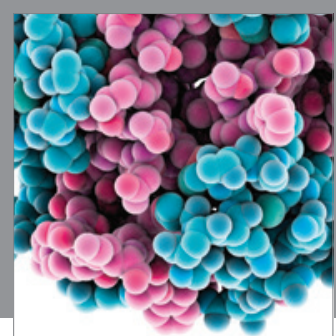

Journal of
Diabetes Research

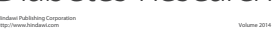

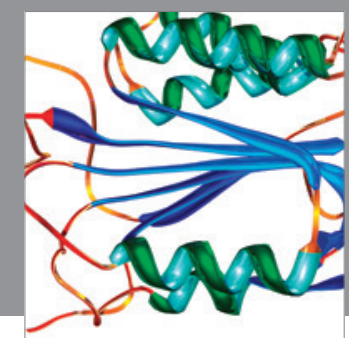

Disease Markers
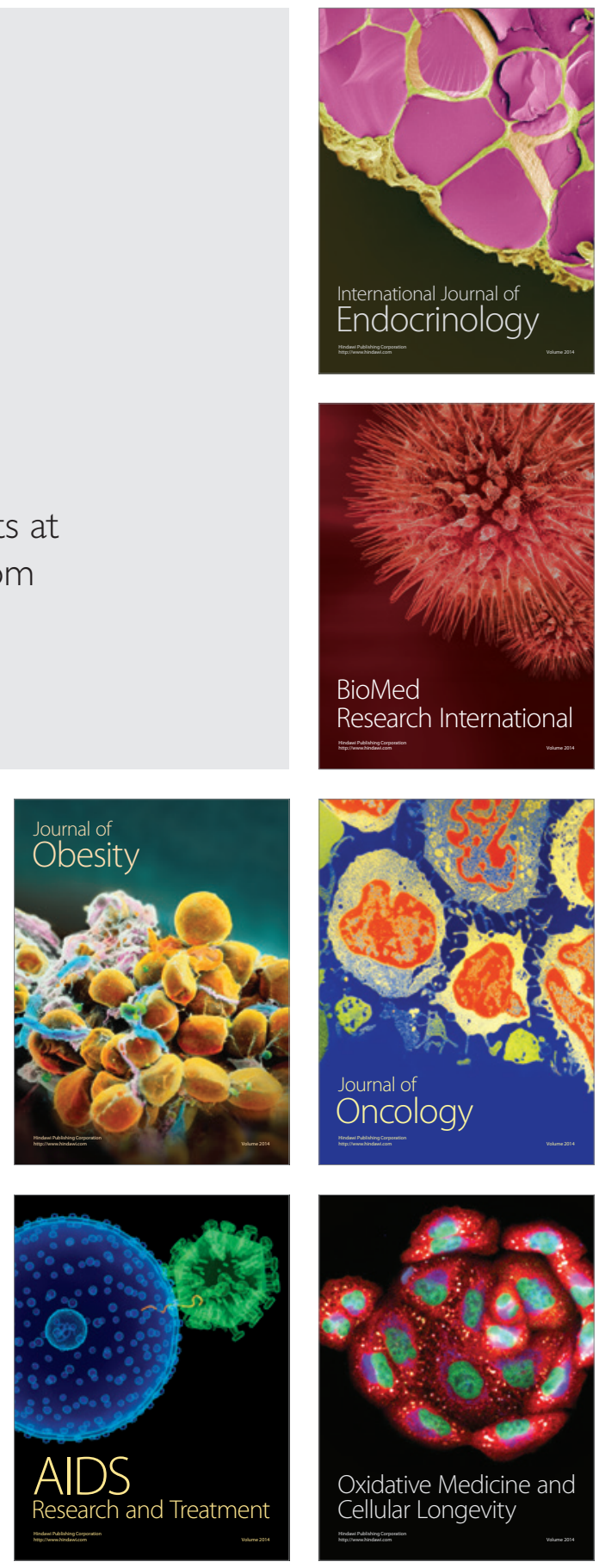